\title{
Research on Children's Collective Smart Piano Teaching
}

\author{
Qinna Xu \\ School of Education \\ Linyi University \\ Linyi, Shandong, China, 273400
}

\begin{abstract}
Accompanying with the improvement of people's income, the people are in a higher and higher demand for quality education. Piano education, as a high-quality educational resource, is valued by parents. Due to the restriction of teaching facilities and faculties, traditional piano teaching is far from satisfying the needs of the society. Therefore, a collective smart piano teaching, which corresponds to the Internet+ trend, becomes popular at the time. It is of great practical significance to improve the efficiency of piano teaching and meet the needs of more people to the piano education through exploring the strategy suitable for smart piano teaching and exerting its strength.
\end{abstract}

Keywords-children; smart piano; collective class; teaching research

\section{INTRODUCTION}

Accompanying with the economic development and improvement of people's living standards in China, quality education has attracted more and more eyeballs, piano education, an important sign of quality education, has been popular in parents. Currently piano has been taken as a required course or selective one in preschool institutions, primary and secondary schools, and more and more parents and instructors have begin to value the children's piano education. It is roughly estimated that as of the end of 2011, there were about 2.65 sets of pianos per 100 families in towns in the country, which doubled compared to 1.3 sets a decade before, by contrast, the people who owned pianos in European cities occupied $50 \%$ of the total, and the popularity rate of piano in Japan reached $25.2 \%$. Seen from this point of view, the popularity rate of piano in China is still lower, besides, children's piano teachers are in a shortage, which have been main factors seriously restricting the development of children's piano education. In order to find a solution for the children's piano education, many schools and training agencies have launched the attempt of smart piano teaching. Smart piano teaching refers to a one by one teaching mode which adopts Internet technology on the basis of user experience to improve the traditional teaching which has lasted for generations, greatly saving faculties and improving the teaching efficiency. However, at present, the children's collective smart piano education is only carried out in higher normal colleges and universities owning adequate conditions, and it is still in a stage to attempt. And the cognitions of most parents and some teachers are still limited to saving faculties, relieving the shortage of piano rooms, lack of equipment, little attentions to public courses. It has been imperative to correctly integrate the methods and theories of smart piano teaching to children's education, and summarize a set of children's smart piano teaching methods practicable and high-quality and fully exert the strength of collective smart piano teaching.

\section{CHARACTERISTICS AND SignifiCANCE OF CHILDREN'S Collective SMART Piano TEACHING}

\section{A. Characteristics of Smart Piano Teaching}

Smart piano is a new teaching with the musical characteristics of the traditional piano kept and a combination of modern technologies (as computer technology, photoelectric technology, digital processing technology, audio sampling technology, etc), it aims at teaching how to play the piano by one by one teaching, a brand-new way to learn music theory, solfeggio, harmony orchestration, simple composition, impromptu accompaniment and so on. Guided by the concept of valuing users' experience, smart pianos are connected to intelligent devices, and mobile Internet technology is implanted to the field of music education, which gives a birth to corresponding teaching APP and realizes new functions endowed by modern technologies such as interactive piano teaching, socialization, games, music games, social sharing, interactive teaching videos and so on, bring more convenience and funs to the piano players. It is extremely suitable for the initial learning to player the piano. Fully understanding of smart piano, smart piano teaching and characteristics of children's collective smart piano will make it better to carry out the children's collective smart piano teaching.

\section{B. Significance of Children's Collective Smart Piano Teaching}

In the Full-time Compulsory Music Curriculum Standard, it is appointed that "music course is an important field of the humanities, one of the main ways aesthetic education and a required one for elementary education, and the music course is valued in four aspects as aesthetic experience, creative development, social interaction and cultural inheritance; take music aesthetics as the core and interests as power for all students, valued personal development, regard the music practice, encourages the music creation, advocate comprehensive disciplines, carry forward the national music 
and understand of multi-culture." Main significance and functions of children's collective smart piano teaching in the country include:

1) Take interests as power and strengthen the enthusiasm to learn: Children (0 to 14 years old under Chinese laws), though different in learning stages, receive education differing from contents, degrees and methods vary, music teachers should not follow traditional teaching mode where teaches teach and students listen, instead, create an easy and pleasant atmosphere for learning, inspire them to overcome difficulties, stimulate their desires for knowledge, make them be confident of professional learning, persevere to the end and ultimately feel the fun of success. For example, as far as the selection of textbooks, first of all, start with the works that students are interested in and familiar with, who are willing to continue learning and master works with different styles. Besides, the functions such as tunes of smart piano can be rationally used in the music teaching platform to fully mobilize the students' enthusiasm to learn, in addition, computers can be used for teaching, with the graphics and characters, listening and singing used, the students may acquire the knowledge with the cognitive space expanded.

2) Advocate overall development and improve students' comprehensive quality: Compared with traditional piano teaching, the collective smart piano teaching owns unique strengths in the following: improving score reading speed, performance level, sensibility, comprehension and expressiveness to music works, synchronization and coordination in brain, eye, hand, ear; brain's associative ability, thinking and learning endurance, imitation, memory and so on. Give full play to the strength of smart piano and control equipment, and guide students to change the passive simple imitation in learning into an interactive multi-channel information exchange, helping students acquire resources around within a limited time and learn more knowledge in the classroom and get more information from classmates. The learning enable students to compete and help with each other.

\section{Strategy OF ChILDREN'S COLLECTIVE SMART PiANO TEACHING}

Smart piano is a new thing just rising in the country, the children's collective smart piano teaching is in an initial period, and there many difficulties and blind spots in the teaching which has been carried out. Relying on years of teaching and research, the author proposes strategies and ways for the children's piano teaching on the basis of actual conditions of children in the piano learning.

\section{A. Set the Children-Centered Concept in Education to Improve Their Interests in Learning.}

The concept in education refers to the understanding and view concerning functions of education, objects, talent training mode, education system, educational structure, educational contents, educational processes and methods, which reflect the wills of social groups according to the equipments of politics, economy and cultural development of that time. The children's collective smart piano teaching should be based on children and establish a children-centered teaching concept, mainly including:

1) Care about the children's comprehensive development: Traditional collective teaching, starting with the cognitivism, gives excessive emphasis on knowledge and skills, but ignoring the needs of children during the piano learning. At present, one of the goals of the piano teaching reform is to change the concept of piano teaching, and the piano teaching should be transferred from caring about the knowledge transmission to the development of students, and the piano education is also transferred from knowledge carrier training to knowledge user. On the one hand, regard the teaching of music knowledge and skills, foster students' professional knowledge and skills; on the other hand, value children's physical and mental health as well as the needs of children in learning and living, care about the music aesthetic ability and innovation so as to promote the students' comprehensive development.

2) Concerned about children's subject status: The collective smart piano teaching should start with "double subjects" in teaching, on the one hand, build a new teacherstudent relation democratic and equal, teachers shall be participants are not masters for teaching, and teachers should respect the student's subject status; on the other hand, teachers should focus on teaching instead of teaching, and the key points shall be what to learn, how to learn, allowing students to learn consciously and actively, allowing students to express different views and correct mistakes and errors if any, teachers and students are equal for communication, keeping mutual communication, mutual inspiration, mutual promotion, forming a music learning community.

3) Care about children's innovation ability: Imitation and inheritance were emphasized in traditional piano teaching, where teachers were able to exert the creativity of their own, which has been inapplicable for the social progress and education development, so the piano shall be centered on innovative spirit and practice ability, fostering students' abilities in creativity, what the teachers should do is not only inheritance but also innovation in education, who are required to work hard to create conditions to combine inheritance and innovation, and enable students to fully exert the subjective initiative and learn actively with creatively and insightfulness.

\section{B. Teaching Strategies for Collective Teaching of the Intelligent Piano}

Teaching strategy refers to the process to control teaching activities based on the clear understanding to achieve the teaching objectives. Generally speaking, the teaching strategies for collective teaching of the intelligent piano can improve children's enthusiasm and ability in playing the piano, and their aesthetic ability as well as humanistic quality, bringing the superiority of the intelligent piano into full play, including:

1) Reasonable grouping: Reasonable grouping is the first step in collective teaching of the intelligent piano. Students are different in personal living environment and the internal music quality. Some children have had basic music knowledge and skills; some have high gift of music; some neither have basis nor have gift and interest, lacking the basic condition and quality in learning music. Teachers should base on the physical 
truth to properly group students and teach collectively according to the unified teaching contents. The number of students in each group should be controlled from ten to fifteen, which is suitable for teachers' instruction and students' learning as well as the interaction between them. Teachers can adjust the groups every half year according to students' performance in class and the scores of final examination.

2) Systematic teaching: The group teaching has higher requirements for teachers. In the traditional "one-to-one" teaching mode, most teachers depend on the experience in the classroom teaching with subjective arbitrariness. While in collective teaching of the intelligent piano, teachers have to teach groups of students. The change of teaching objects has stricter requirements for teachers and less preparation. Teachers must have strong ability of class organization and inspire students' interest and enthusiasm; have experience in teaching the piano and good language expression ability; grasp the systematic teaching and the integral structure, paying attention to the application of teaching methods, accurate and vivid performance as well as systematic and thorough analysis. In order to meet the needs of normal college students in the employment, teachers should let students know what it is and know why it is in teaching knowledge and skills. Therefore, the systematic teaching plays an important role in collective teaching of the intelligent piano. Meanwhile, teachers should guide students to digest the knowledge and skills, learn to find and solve problems as well as improve the learning ability.

3) Cooperative learning: The cooperative learning refers to a teaching form that two or more than two individuals learn together and promote each other in order to improve the learning effect. It includes the cooperation between students as well as between teachers and students. It involves the communication of learning information, language expression, ideological and spiritual communication, as well as the adaptation of character, in order to train students' ability of communication and independent learning and promote the development of students' self-concept and collectivism value. In collective teaching of the intelligent piano, teachers should guide reasonably to let students realize and improve the team spirit and cooperation ability in learning, exerting the unique effect of collective teaching.

3) Collective class recall: The class recall is also called "class return", one of the teaching links of music technology class. In the teaching of vocal music, instrumental music and solfeggio, students are required to sing or perform the tasks assigned in the last class in front of teachers, so that teachers can check whether there is progress or error and give further guidance. The class recall in collective teaching of the intelligent piano has the advantages beyond the reach of the traditional "one-to-one" teaching. The form of small concert with collective participation strengthens the classroom atmosphere of artistic practice and provides students with the opportunity to perform and communicate with other students, strengthen their competitive spirit as well as learning enthusiasm. At the meantime, students can learn from each other through appreciating the performance of other students. It can better stimulate students' subjective initiative in learning. In the collective class recall, unison, rotational performance, solo, relay and group competition can be applied alternately to activate the classroom climate, arouse students' learning interests and attentions. In unison, students can perform the track learnt in the last class together, and then the teacher points out strength and weakness, further making definite requirements; in the group competition, students can be divided into two groups: one group performs and the other group listens, finding deficiencies through analysis and discussion. The relay uses the form of small concert, requiring the participation of all students. Each student is both the performer and the listener. They play a track in turn. The teacher neither guides nor stops them in the performance to keep the atmosphere of the concert, in order to strengthen the effects of students' artistic practice. The performance effect of reprise and tutti is superior to that of solo and union. It is easier to stimulate students' enthusiasm. Therefore, the above contents can be added properly to let students enrich knowledge and improve themselves in the happy and efficient atmosphere.

\section{CONCLUSION}

Dan Zhaoyi, a famous piano educator of our country once said, "The essence of the piano education is the education of music quality". The effects of music art on the human spirit, emotion, soul and character make the music education become an important part of quality-oriented education in our country. Therefore, the piano education becomes increasingly popular in the society. It is necessary to reform the traditional methods in the piano teaching, so as to meet the requirements of more people in receiving the piano education and arouse the interests of children in learning the piano. In the internet plus era, the mass teaching on the intelligent piano becomes more superior. We have reasons to believe that with the popularization of intelligent mass teaching, the piano education of our country will prosper and develop, and the aesthetic ability and comprehensive quality of Chinese people will improve greatly.

\section{REFERENCES}

[1] Zhou Ludan, Intelligent Piano: Use "Intelligence Plus" to Shake the Piano Manufacturing Industry, New Economy Weekly, 2016(3)

[2] Chen Rui, Transformation and Influence of Intelligent Piano, Northern Music, 2016(7)

[3] Qian Zhimei. Research on the Piano Teaching under the Background of Intelligent Interaction, Hundred Schools in Arts, 2014(7). 